\title{
Social economic aspects of COVID-19 Pandemic - a brief summary
}

\author{
Regina Hoi Yee Fu \\ School of Economics, Senshu University, Japan
}

\begin{abstract}
The COVID-19 pandemic has resulted in over millions confirmed cases and over hundred thousand of deaths globally. It has brought difficult situations for citizens of nations across the world, and have sparked fears of an impending economic crisis and recession. Policy markers and public managers worldwide are put on the test on their crisis management capability. This paper is the summary that I presented in The Fourth Conference on Sustainability Science organized by the Center for Environment and Sustainability Science, University of Padjadjaran (UNPAD) on $8^{\text {th }}$ October, 2020. In this paper, the responses and impacts of COVID-19 pandemic of Asian and African countries will be introduced. Learning from these experiences, we seek for hints that would be needed for the sustainable recovery of the Post Pandemic COVID-19 global society.
\end{abstract}

\section{The outbreak}

As of October 4, 2020, there have been 34,747, 785 confirmed cases of COVID-19, including 1,030, 160 deaths, reported to the World Health Organization (WHO). The most affected region is Americas, which accounts for $49 \%$ of the total confirmed cased.

As illustrated in the Global and Regional time line, in late December 2019 WHO China Country Office has been informed of cases of pneumonia of unknown etiology detected in Wuhan City, Hubei Province of China [2]. On January 7, 2020, Chinese authorities identified a new type of coronavirus (novel coronavirus, SARS-CoV-2) from a cluster of the outbreak. SARS$\mathrm{CoV}-2$ was a new strain of coronavirus that has not been previously identified in humans. The initial cases were thought to be linked to the Hunan seafood market which has been closed on January 1,2020. Possible sources are still under investigation by the Chinese authorities and international institutes.

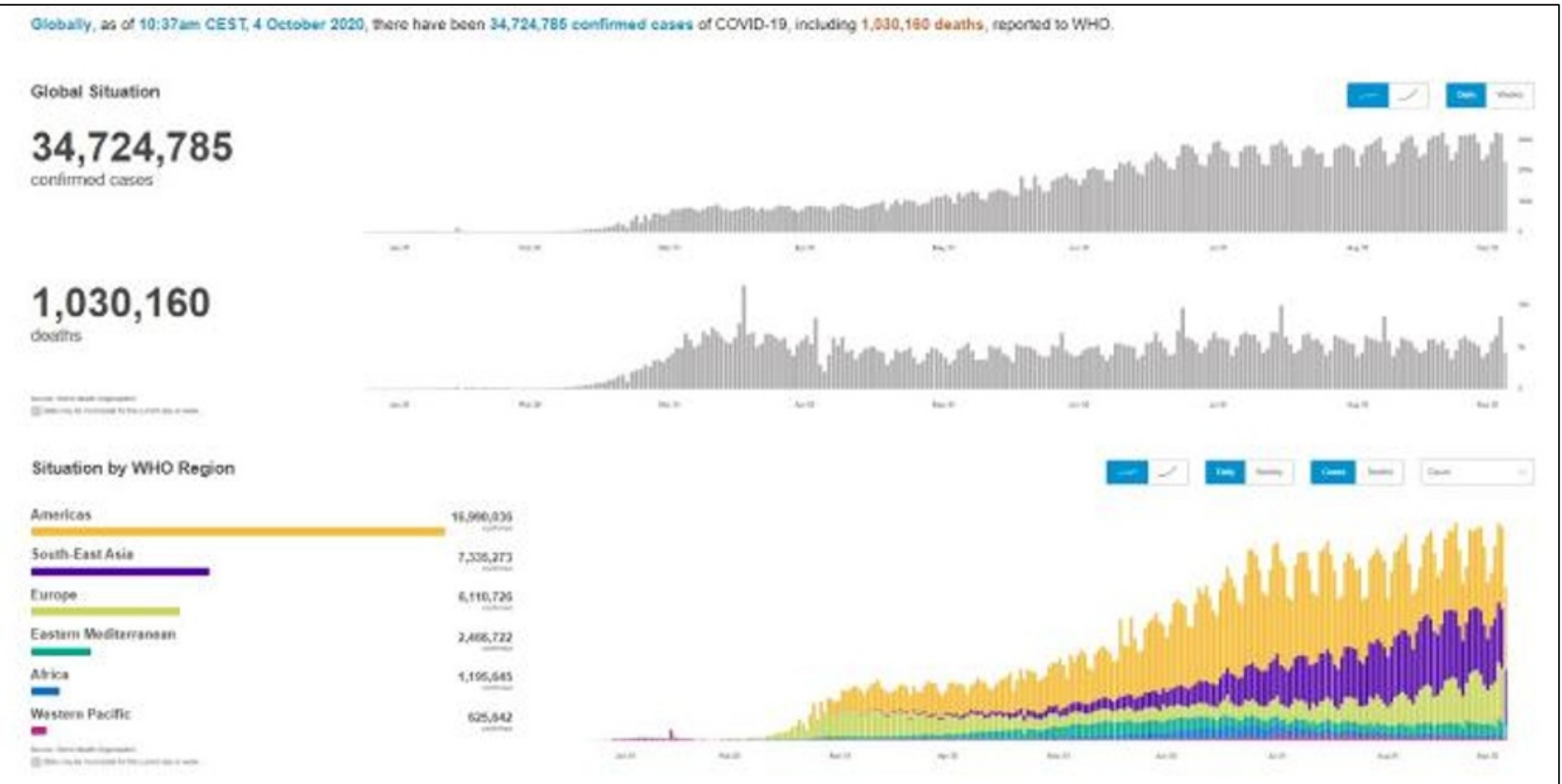

Pig. 1. Source: WHO, 2020a 


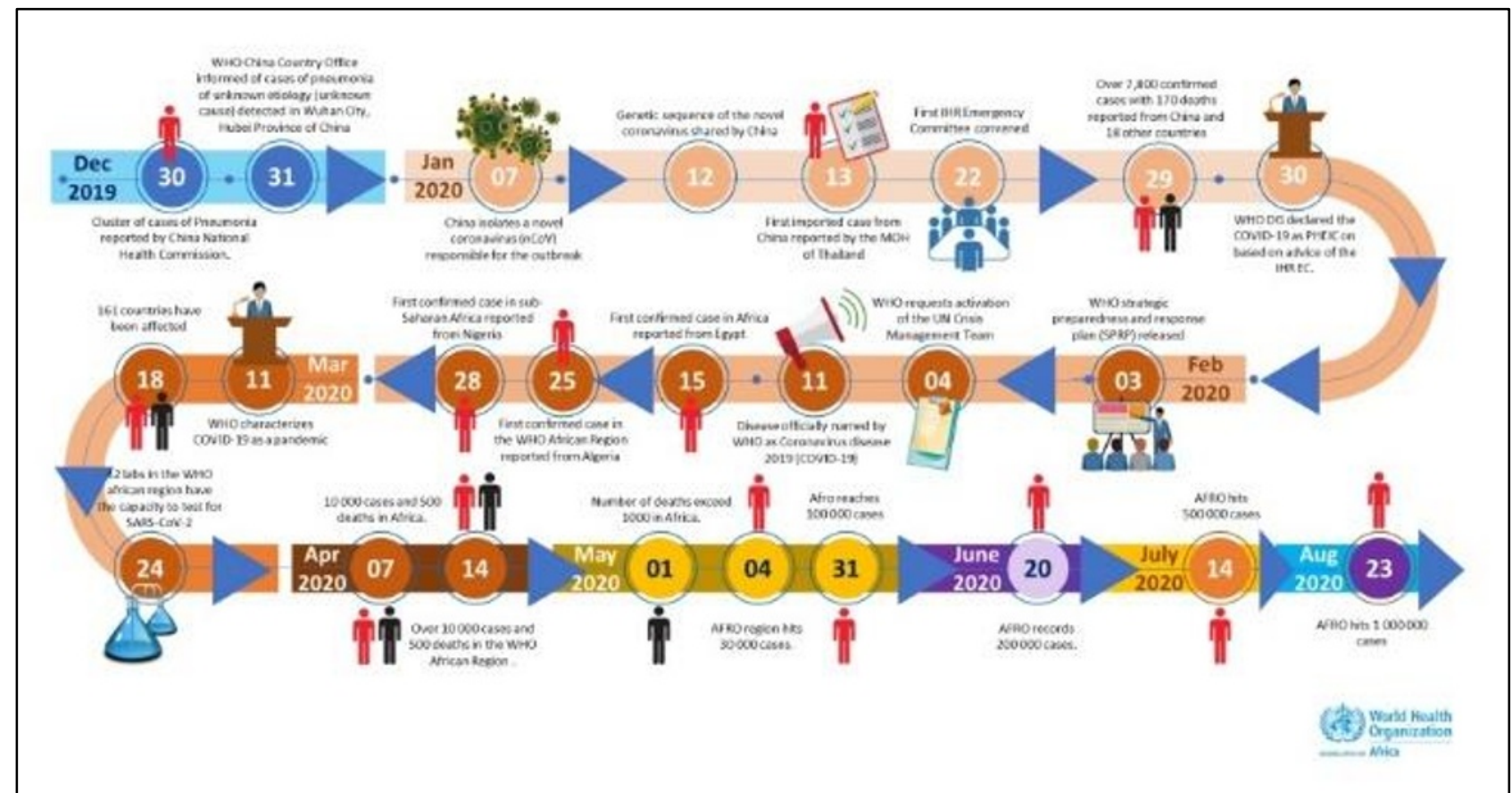

Pig. 1. Source: WHO, 2020b

Within a short period, the number of reported cases increased exponentially. By the end of January, there have been over 7,800 confirmed cases with 170 deaths reported from China and 18 other countries. The infection has spread to the far African continent with the first confirmed cases reported from Egypt on February 15. Risk assessment by WHO was raised from "high" to "very high" on 28 February 2020, and eventually on March 11, WHO Director-General officially characterized the COVID-19 as a pandemic.

Regarding the number of confirmed case and death per million, the USA is one the most seriously affected countries by COVID-19. As of October 4, 2020, USA reported 635.32 death per million, which was tremendously higher than the other Asian countries.

Table 1. Covid-19 deaths per million population as of Oct 4,

\begin{tabular}{|l|l|l|l|l|}
\multicolumn{7}{l}{$\begin{array}{c}2020 . \\
\text { Country }\end{array}$} & $\begin{array}{l}\text { Confirmed } \\
\text { case }\end{array}$ & $\begin{array}{l}\text { Confirmed } \\
\text { death }\end{array}$ & $\begin{array}{l}\text { Death per } \\
\text { million }\end{array}$ & $\begin{array}{l}\text { Population } \\
\text { (in millions) }\end{array}$ \\
\hline USA & $7,382,194$ & 209,382 & 635.32 & 329.57 \\
\hline China & 90,604 & 4,739 & 3.40 & $1,394.02$ \\
\hline Singapore & 57,800 & 27 & 4.35 & 6.21 \\
\hline Japan & 85,345 & 1,594 & 12.70 & 125.51 \\
\hline South Korea & 24,091 & 421 & 8.12 & 51.84 \\
\hline Taiwan & 514 & 7 & 0.30 & 23.60 \\
\hline
\end{tabular}

Source: Calculated based on data from WHO and World Population Clock.

\subsection{China}

Soon after the early reported cases, the Chinese authorizes have instituted unprecedented measures to contain the virus from mid-January 2020. The Wuhan city was put in lockdown. Flights and trains were suspended, and roads were closed. Strict measures of isolation were implemented around the country, with almost all the country's population were told to stay home. Public gatherings were banned, and entertainment venues, schools, workplaces were closed. Although the initial response of China has been criticized as slow, the extremely aggressive measures at all levels stopped the epidemic in its trajectories in China, which succeeded to quickly peak down and limit most of the death within the Hubei province [1]. By October 2020, social life in China has mostly returned to normal. Half a billion of the population travelled all around the country to celebrate the national holidays period, which marked the economic recovery of China lifting its neighbors in Asia.

\subsection{Singapore}

Singapore was the third country to report cases of COVID-19. Because of its high population density, at that time the world worried that it would be the worsthit country outside China. Learned from the 2003 SARS epidemic, Singapore responded rapidly and aggressively to the virus. Beside imposing travel restrictions on passengers coming from China, contact tracers were applied on patients to create detailed activity log and to identify people who have been in close contact with the infected. Once a person was identified, he would be quickly isolated and his contacts were then tracked again. A small phone app was created to allow authorities to identify individuals accurately. The aggressive contact-tracing measure was effective, but Singapore soon faced a new wave of infections of which $75 \%$ were linked to migrant workers. To tackle with the new infections, Singapore has tightened entry restrictions, closed nonessential business, and reinforced strict order on social distancing. Despite having the world's best airport, photo of the almost empty Changi Airport showed waring of a "daunting period" of the Singapore economy as the pandemic still showed no signs of abating. 


\subsection{Japan}

Japan responded to the initial COVID-19 outbreak by repatriating Japanese citizens from Wuhan and initiating border control regulations. As the number of community-spread increased, Japan prioritized its policy on restricting large-scale clusters. A one-month "state of emergency" order was declared on April 7, 2020 that allowed the government to impose social distancing measures, such as instructing residents to avoid unnecessary outings and restricting business and facilities. The widespread use of facial masks along with the greeting customs of bowing instead of handshaking might have played a role in slowing down infection in Japan. As a highly dense country with the world's highest proportion of senior citizens, Japan relied largely on its group mentality of putting collective before the self and respecting for order to promote compliance with social distancing measures to bring COVID-19 outbreak under control. As of October, Japan ranked low in numbers of people testing positive for COVID-19, but some questioned whether Japan and its municipal governments have been conducting enough tests. To boost the economy, Japanese government launched the "Go To Travel" campaign to promote domestic tourism. The campaign was expected to run until spring 2021, but as the number of confirmed cases sharply increased in December, the campaign was then interrupted. There is a high uncertainty concerning the Tokyo Olympic and Paralympic Games postponed to the summer of 2021 .

\subsection{South Korea}

The first appearance of COVID-19 in South Korea was reported on January 20, 2020, then the number of confirmed cases rose very quickly. Since MERS outbreak in 2015, South Korea has improved its response to infection outbreak. The country quickly developed diagnostic kits and implemented large-scale testing to identify and quarantine infected and potentially infected cases. Many Koreans were tested at convenient drive-through and walk-through facilities. The government also provided free smartphone apps to alert people. The app allowed patients to input symptoms to get diagnosed or connected to a doctor for screening. Contact-tracing programs that consisted official interview, GPS tracking and video surveillance have been effective in the country that the virus was largely controlled at bay within a month without no large-scale lockdowns or extreme measures.

\subsection{Taiwan}

Taiwan started inspecting passengers for COVID-19 symptoms since the first WHO notification in early January. By integrating National Health Insurance Database with immigration and custom databases, Taiwanese government generated alert on patient's travel history and clinical conditions. Passengers were triaged in airport with their infectious risks classified. For individuals with high risks, they were asked to quarantine at home and their movement be tracked through mobile device. Proactive measures of border controls, effective use of big data and technology, and strict home-quarantine order have made Taiwan one of the most successful governments in trapping the infection from spreading.

\subsection{Africa}

As of late April, the African continent has remained relatively unaffected by COVID-19 (WHO, 2020b). With very unstable health systems and increased travel links over the past years, Africa became the most vulnerable continent to infectious diseases. After the outbreak, WHO, Africa Centers for Disease Control and Prevention (CDC), national governments, and public health organizations have spent two months scaling up preparedness efforts. Recommendations made by the International Health Regulations Emergency Committee were implemented. Since the first reported case in February there has been an upsurge in confirmed cases. By September 30, there were 1,175,271 confirmed cases and 25,825 deaths in the WHO African Region. The highest number of cases was recorded in South Africa $(9,290,37 \%)$, followed by Ethiopia $(4,162$, $16 \%)$, Mozambique $(1,442,6 \%)$, Uganda $(1,305,5 \%)$ and Kenya $(1,154,5 \%)$. The top five countries of deaths in the region were South Africa, Algeria, Ethiopia, Nigeria, and Kenya $(21,402,83 \%)$. Africa represented $3.5 \%$ of confirmed cases and $2.6 \%$ of deaths reported worldwide, with South Africa be the hardest hit country, eighth globally, but there was a relatively low number of deaths.

\section{On the way forward}

Extreme measures of lockdowns, large-scale suspension of business and schools, strict stay-at-home orders have been implemented in many countries. These measures were not sustainable in the long-term and involved enormous cost. However, in face of the novel virus, well-organized planning, and implementation, early and quick response to virus outbreak, effective dissemination of information, public support and fully compliance with government's measures have played significant roles in weathering the storms.

Prompt, strong and coordinated responses would still be needed. Government would need to play immediate focus and implement strong measures to contain the spread of the disease and to treat the infected. Economic measures would need to be peculiar to the present situation. Before international trade could return to normal, more efforts would be required to develop local economy and reduce dependence on importation. Private sectors would need to relieve their employees of their jobs, allowing them to work from home. There would be more online engagements of business and education. Meanwhile, government intervention would be needed to help small and medium sized enterprises to sustain this difficult time. Government might take this chance to look at the cost of governance. For the poorest countries, suspension or cancelation of international 
debts would be necessary. In the long-term, countries must strengthen economic diversification and national health and social protection. Sound fiscal policy and financial, industrial and trade policies would be expected from the population.

\section{References}

1. Lu, N., Cheng, KW., Qamar, N., Huang, KC., Johnson, JA., Weathering COVID-19 storm: Successful control measures of five Asian countries, American Journal of Infection Control, 48: 851-852 (2020)

2. World Health Organization (WHO), (2020a), https://www.who.int (accessed on 23th December, 2020) 